Article

\title{
Calculating the Interface Flow Limits for the Expanded Use of High-Voltage Direct Current in Power Systems
}

\author{
Sangwook Han $(\mathbb{D}$
}

Electrical Information Control Department, Dong Seoul University, Seongnam-si 13117, Korea; hswrain@du.ac.kr

Received: 22 April 2020; Accepted: 29 May 2020; Published: 4 June 2020

check for
updates

\begin{abstract}
Although loads are increasingly becoming concentrated in metropolitan areas, power generation has decreased in metropolitan areas and increased in nonmetropolitan areas; hence, power transmission must occur through interface lines. To achieve this, additional transmission lines must be secured because the existing interface lines have reached their large-scale power transmission limits. The Korea Electric Power Corporation has installed many high-voltage direct current lines, thereby impacting the determination of interface power flow limits. These serve as the basis for system operations. However, knowledge of operating high-voltage direct current lines as a simple transmission line in a single power system is lacking. The effects of high-voltage direct current and its related parameters for interface flow limit analysis remain unclear. Furthermore, whether high-voltage direct current should be included in the selection of the interface lines that serve as the basis for interface flow remains unclear. In addition, whether the high-voltage direct current line faults should be included in the contingency list for determining the interface flow limits has not been considered. Additionally, it has not been determined whether to operate the DC tap when performing the simulation This study addresses these issues and determines the conditions that are necessary for determining the interface flow limits when a high-voltage direct current transmission facility has been installed in a land power system. The results conclude how to reflect the above conditions reasonably when performing the interface flow limit analysis on a system that includes the HVDC lines.
\end{abstract}

Keywords: contingency list; DC tap control; FV analysis; FV margin; HVDC; interface lines; interface power flow; power system operation

\section{Introduction}

In Korea, the electricity industry is being restructured owing to increasing oil prices, and efforts are being made to operate low-cost generators and reduce the maximum loads. Simultaneously, researchers are investigating new distributed power sources, such as photovoltaic and wind generators, as well as methods to connect them to the grid. Nevertheless, the demand for power continues to increase because of economic growth. Moreover, although distributed power sources are expected to reduce the concentrated loads in metropolitan areas, they are usually set up in nonmetropolitan areas where the land cost is low. This leads to a significant regional imbalance between the power generation and the load. The loads continue to be concentrated mainly in the metropolitan areas. However, low-cost generators are concentrated in seaside areas, such as the west coast. Recently, large-scale power generators have also been set up on the east coast. Furthermore, generators in the Incheon metropolitan area are near the end of their life and cannot generate power any-more. Power generation decreases in metropolitan areas and increases in the nonmetropolitan areas. Thus, interface lines will eventually be required for large-scale power transmission [1-4]. However, the existing interface lines have reached 
their limits for large-scale power transmission; therefore, there is an urgent need to secure additional transmission lines.

The Korea Electric Power Corporation (KEPCO) tried to secure transmission lines in early 2010. However, since the construction of the Bukgyungnam-Singori $765 \mathrm{kV}$ transmission line, they have found it very difficult to build more transmission lines owing to collective complaints from local communities. In particular, many local organizations are opposed to the construction of transmission towers, and they have constantly demanded the construction of underground lines. As a result, high-voltage direct current (HVDC) lines, which can transfer substantial amounts of power and are advantageous for the construction of underground lines, are under construction on a large scale, even for the land power system $[5,6]$.

To operate power systems in a stable manner, it is critical to ensure the robustness of the power system with respect to the voltage/reactive power, as observed by performing a voltage stability analysis. Recently, domestic power systems have been operating near their stability limits under a heavy load. This is because of the continuous increase in the load and the reactive power loss, which is increasing owing to the use of long-distance transmission lines to mitigate the imbalance between the supply and the demand areas. Therefore, to secure sufficient voltage stability for the domestic power system and to establish an appropriate operation strategy and voltage control plan, detailed voltage stability analyses and reviews are essential [7-14].

The Korea Power Exchange uses the interface flow limits in metropolitan areas as the basis for the voltage stability analysis of domestic power systems. The interface flow can be forcibly increased by reducing the power generation in the metropolitan area while increasing the power generation in the nonmetropolitan area without increasing the load of the system. The analysis of the interface flow limit (FV) is concerned with the extent to which the interface flow can be increased in terms of voltage stability [15-18]. The system is operated based on the interface flow limits, which is determined in this manner. The margin is set from the calculated value to operate the system within the limit. Therefore, the method used to determine the interface flow limit has a critical influence on the system operation.

As described earlier, KEPCO plans to include many HVDC lines in its land power system. This has already been reflected in the 8th Basic Plan for Long-term Electricity Supply and Demand announced by the Ministry of Trade, Industry, and Energy in December 2017. This includes many HVDC lines in the eighth power system database [5]. However, because the experience of operating HVDC lines as a simple transmission line in a single power system is lacking, the effects of HVDC systems and various HVDC-related parameters on interface flow limit analyses have not been studied [19-23]. Furthermore, it remains unclear whether the HVDC lines should be included in the selection of interface lines that serve as the basis for interface flow limit analysis and whether the HVDC line faults should be included in the contingency list for determining the interface flow limits.

This study aims to determine the conditions that are required for determining the interface flow limits when a HVDC transmission facility is installed in a land power system. This investigation also explores whether the HVDC lines should be included in the interface lines, whether the HVDC line faults should be included in the contingency list, and whether the HVDC analysis option, which can influence the interface flow limits, should be added. In particular, this study thoroughly investigates how the interface flow limits change according to the DC Tap setting in the FV analysis option. Because the reactive power is usually consumed to increase the voltage using the DC Tap [24-29], among the various HVDC parameters, the DC Tap parameters will influence the voltage as well as the interface flow limits that correspond to the static analysis.

The rest of this paper is organized as follows. Section 2 describes the transmission and substation facility plan of KEPCO's 8th Basic Plan for Long-term Electricity Supply and Demand and the FV analysis. In Section 3, a case study is performed to investigate the phenomena that arise when the HVDC lines are included in the interface lines and when the HVDC line faults are included in the contingency list. This section also derives the interface flow limits and the comparative review results according to the 
DC Tap simulation conditions. Section 4 concludes this study by summarizing how to reflect the above conditions reasonably when performing the FV analysis on a system that includes the HVDC lines.

\section{8th Basic Plan for Long-Term Electricity Supply and Demand and FV Analysis}

\subsection{Transmission and Substation Facility Plan of the 8th Basic Plan for Long-Term Electricity Supply and Demand}

Owing to the increasing demand for power, the existing transmission lines must be reinforced, or new ones must be established to improve the stability of the domestic power system. This will enable a stable power supply in load-concentrated areas.

Therefore, facilities whose construction has been delayed are being prioritized, and alternatives are being developed. In particular, HVDC systems are being extensively applied worldwide because HVDC facilities provide advantages such as small-sized steel towers, the low generation of electromagnetic waves, and good efficiency for long-distance and large-scale transmission. Table 1 shows the current state of major domestic transmission lines [5].

Table 1. Current State of Major Domestic Transmission Lines.

\begin{tabular}{cccc}
\hline No. & Transmission Line Path & Completion Date & Voltage \\
\hline 1 & Bukdangjin-Goduk\#1 & December 2019 & \\
2 & Bukdangjin-Goduk \#2 & June 2021 & 500 kV HVDC \\
3 & Sinhanul\#1-Singapyeong & December 2021 & \\
4 & Sinhanul\#2-Metropolitan area\#2 & December 2022 & \\
5 & Bukdangjin-Sintanjung & December 2018 & \\
6 & Gwangyang C/C-Sinyeosu & October 2020 & \multirow{2}{*}{$345 \mathrm{kV}$} \\
7 & Dangjin T/P-Sinsongsan & June 2021 & \\
8 & Goduk-Seoansung & June 2021 & \\
\hline
\end{tabular}

The HVDC transmission line between Bukdangjin and Goduk has been built to reinforce the transmission line that is currently used to transmit the power generated in Chungnam province to the metropolitan area. The Sinhanul\#1-Singapyeong and Sinhanul\#2-Metropolitan area\#2 HVDC transmission lines are being built to connect large-scale power generation on the east coast with the power system. The Bukdangjin-Sintangjung and Dangjin T/P-Sinsongsan $345 \mathrm{kV}$ transmission lines, as well as the Bukdangjin-Goduk $500 \mathrm{kV}$ HVDC transmission lines, are being built to reinforce the transmission lines that are currently being used to transmit the power generated in Chungnam province. The Gwangyang $\mathrm{C} / \mathrm{C}-$ Sinyeosu $345 \mathrm{kV}$ transmission line was recently built to address the developmental restrictions in the Yeosu area and to supply power for the industrial complexes. Finally, the Goduk-Seoanseong $345 \mathrm{kV}$ transmission line is being built to expand the interface lines of the metropolitan area.

Table 2 shows the current state of the major new substations (converter stations). The Sinjoongbu $765 \mathrm{kV}$ substation was recently built to supply power to and resolve the voltage instability in the Joongbu area. The Bukdangjin, Goduk, Sinhanul\#1, Sinhanul\#2, Singapyeong, and Metropolitan area\#2 converter stations have been recently built to transmit the regional power generation to the metropolitan area. Finally, the Goduk $345 \mathrm{kV}$ substation was built to supply power to the southwestern area of the Gyeonggi province and the Pyeongtaek area.

Table 2. Current State of the Major Substations (Converter Stations).

\begin{tabular}{cccc}
\hline No. & Substation (Converter Station) & Completion Date & Voltage \\
\hline 1 & Sinjoongbu & June 2019 & $765 \mathrm{kV}$ \\
2 & Bukdangjin C/S, Goduk C/S & December 2019 & $500 \mathrm{kV} \mathrm{HVDC500} \mathrm{kV}$ \\
3 & Sinhanul\#1 C/S, Singapyeong C/S & December 2021 & HVDC500 kV HVDC \\
4 & Sinhanul\#2 C/S, Metropolitan area\#2 C/S & December 2022 & 345 kV \\
5 & Goduk & June 2018 & \\
\hline
\end{tabular}




\subsection{Current State of the Interface Lines}

Although many interface lines currently supply power to the eastern and southern areas owing to the loads in the metropolitan areas, the continuous increase in load has necessitated the reinforcement for power transmission between these areas. Figure 1 shows the domestic power system reflecting the 8th Basic Plan for Long-term Electricity Supply and Demand, and Table 3 shows the current state of the interface transmission lines [24].

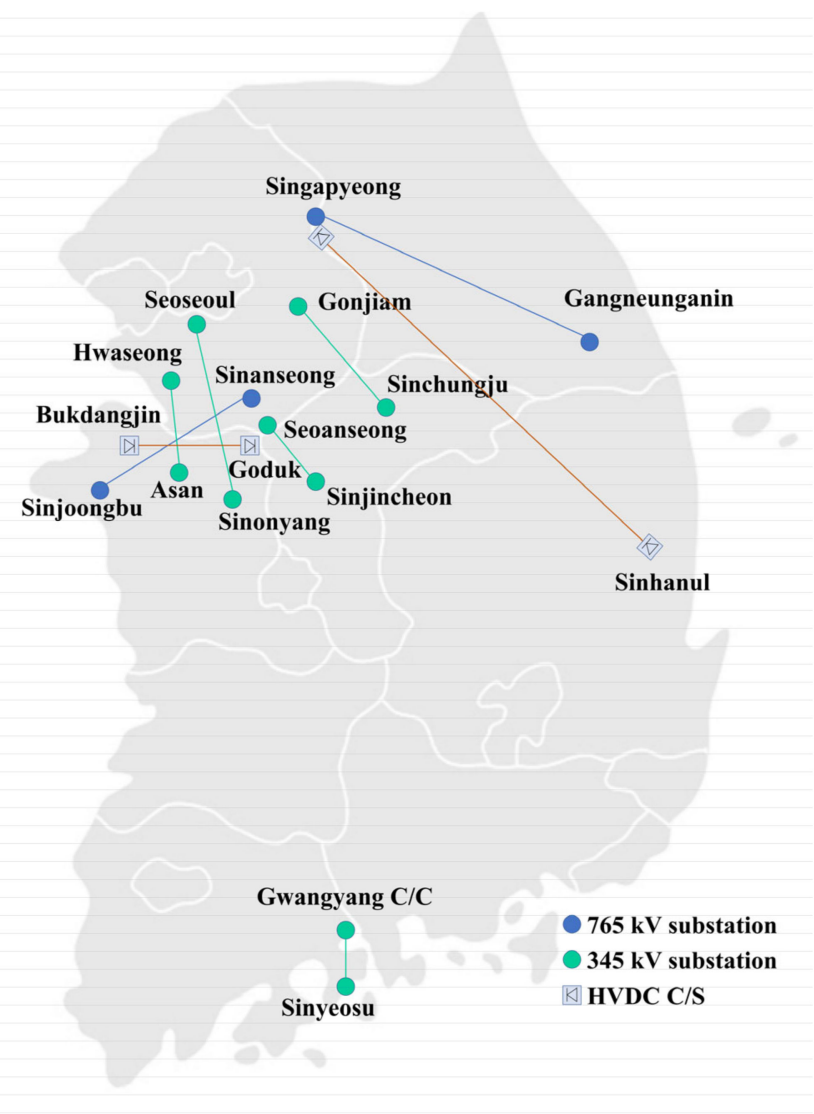

Figure 1. Domestic power system diagram.

Table 3. Current State of the Interface Transmission Lines.

\begin{tabular}{ccccc}
\hline No. & $\begin{array}{c}\text { Interface Transmission } \\
\text { Line (From) }\end{array}$ & $\begin{array}{c}\text { Interface Transmission } \\
\text { Line (To) }\end{array}$ & No. of Lines & Voltage \\
\hline 1 & Sinjoongbu (4010) & Sinanseong (4020) & 2 & $765 \mathrm{kV}$ \\
2 & Gangneunganin & Singapyeong & 2 & $765 \mathrm{kV}$ \\
3 & Asan (4400) & Hwaseong (6950) & 2 & $345 \mathrm{kV}$ \\
4 & Sinonyang (4600) & Seoseoul (4850) & 2 & $345 \mathrm{kV}$ \\
5 & Sinchoongju (4750) & Gonjiam (5750) & 2 & $345 \mathrm{kV}$ \\
6 & Sinjincheon (4300) & Seoanseng (4800) & 2 & $345 \mathrm{kV}$ \\
\hline
\end{tabular}

The domestic power system contains six interface lines. Two $765 \mathrm{kV}$ lines are for Sinjoongbu-Sinanseong and Gangneunganin-Singapyeong operations, and four $345 \mathrm{kV}$ lines are for Asan-Hwaseong, Sinonyang-Seoseoul, Sinchoongju-Gonjiam, and Sinjincheon-Seoanseong operations. These lines transmit power, which are generated on the east coast and in the south to the load-concentrated metropolitan areas. 


\subsection{FV Analysis}

FV analysis is used to determine the stability by dividing a single power system into two areas and increasing the flow of the interface lines connected between these two areas. Figure 2 shows the flow of an interface line after dividing a single power system into areas A and B [30].

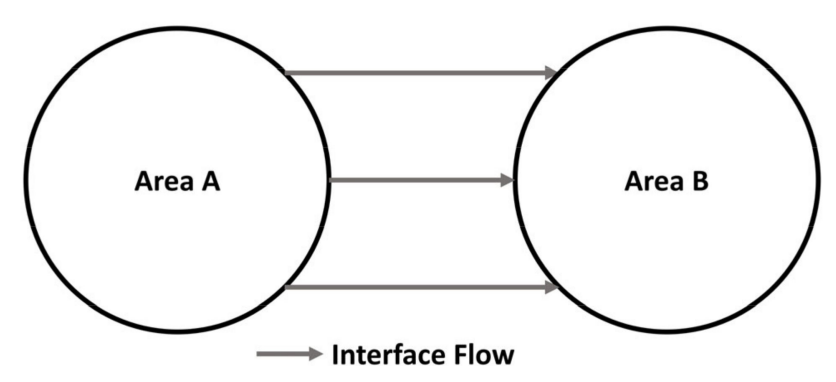

Figure 2. Simple power system diagram for interface flow limit (FV) analysis.

Figure 2 demonstrates that if the power generation cost in area $\mathrm{A}$ is lower than area $\mathrm{B}$, the power generation in area $\mathrm{A}$ is increased and area $\mathrm{B}$ is decreased for the economical operation of the power system. If the interface flow continues to increase, it will eventually be constrained by voltage stability. To implement the interface flow analysis algorithm, the parameter $\lambda$, which represents the shift in generation, is incorporated into the power flow equation [31]. Here, it is necessary to verify the point at which the voltage stability limit occurs owing to the increase in the interface flow of the interconnected line to area $\mathrm{B}$.

Area A, where power generation increases, is

$$
P_{G A i}=P_{G A i 0}+\lambda k_{G A i} P_{G A 0, \text { total }}
$$

Area B, where power generation decreases, is

$$
P_{G B i}=P_{G B i 0}-\lambda k_{G B i} \Delta P_{G A, \text { total }}
$$

Hence, the total is

$$
\triangle P_{G A, \text { total }}=\Sigma \lambda k_{G A i} P_{G A 0, \text { total }}
$$

where $P_{G A(B) i 0}$ is the original active power of bus $i$ in area $\mathrm{A}$ or $\mathrm{B}, P_{G A 0 \text {,total }}$ is the original total power generation of area $\mathrm{A}, \Delta P_{G A \text {,total }}$ is the change in total power generation of area $\mathrm{A}, k_{G A i}$ is the increased power burden of bus $i$ in area $\mathrm{A}, k_{G B i}$ is the increased power burden of bus $i$ in area $\mathrm{B}$, and $\lambda$ is the parameter of the iteration step.

The above equation indicates that for the area where the power generation increases, the sum of the original active power of each bus in the area and the original total power generation is multiplied by the power generation parameter $\left(k_{G A i}\right)$ that is burdened by each power generation bus. This is the amount of power that is required in the power generation bus. For the area where the power generation decreases, the following operation can be performed to determine the amount of power that is required in the generation bus. The original total power generation is subtracted and then it is multiplied by the power generation parameter $\left(k_{G B i}\right)$. This is burdened by each power generation bus from the original active power for each bus in the area. Figure 3 presents a graph that is obtained using the above equation. For a curve with the smallest limit after an accident, if the power generation at the limit is maintained and the curve returns to the pre-accident state by removing it, the difference between the regressed limit point and the current operating point becomes the interface flow margin. If a failure occurs, this is where the system can operate stably. 


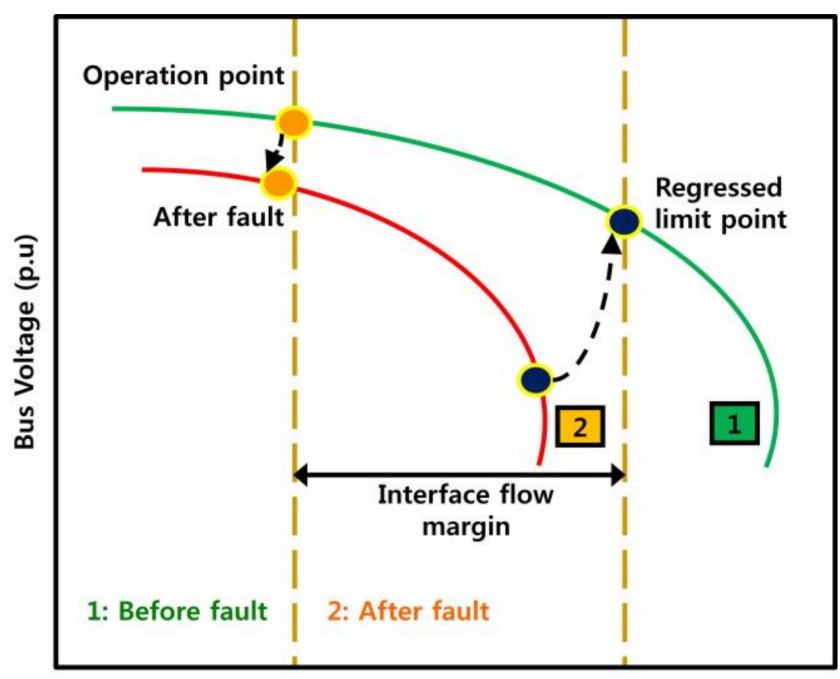

Interface flow (MW)

Figure 3. Interface flow margin from the FV curve.

\subsection{Tap Setting}

The DC Tap is the tap of a converter in the HVDC converter station. The converter is a facility that is used to convert the voltage of the conventional AC system into DC voltage to transmit the DC through the HVDC system. The DC Tap keeps the voltage constant by switching the tap, which depends on the status of the power system. This is done in a manner that is similar to the transformer tap of the conventional AC system.

Table 4 shows the DC Tap parameters [32]. The transformer ratio is the voltage ratio between the primary side and the secondary side of a converter. The normal tap setting refers to the tap setting value in the normal state and the max. tap setting and min. tap setting refers to the maximum and minimum tap setting values, respectively. The tap step refers to the changed value when the tap in a converter is switched once. These parameters can be modified in the relevant HVDC branch data.

Table 4. Direct current (DC) Tap Parameters.

\begin{tabular}{ccccc}
\hline No. & Parameter & $\begin{array}{c}\text { Bukdangjin-Goduk } \\
\text { HVDC }\end{array}$ & $\begin{array}{c}\text { Sinhanul-Metropolitan } \\
\text { Area HVDC }\end{array}$ & $\begin{array}{c}\text { Default in } \\
\text { PSS/E }\end{array}$ \\
\hline 1 & Transformer ratio & 0.6377 & 0.6125 & 1.0 \\
2 & Normal Tap Setting & 1.0 & 1.0 & 1.0 \\
3 & Max. Tap Setting & 1.0 & 1.31 & 1.5 \\
4 & Min. Tap Setting & 1.0 & 0.91 & 0.51 \\
5 & Tap Step & 0.0125 & 0.0125 & 0.00625 \\
\hline
\end{tabular}

\section{Case Study}

\subsection{Simulation Results When Including HVDC Lines in the Interface Lines}

In the FV analysis, identifying interface lines is critical because this determines the $x$-axis of the graph. In a conventional system that does not include the HVDC lines, the six main interface lines (AC) in Table 3 are selected that have the greatest influence on the system. The process of each simulation is as follows. The power generation capacity of the metropolitan area is reduced, and the power generation capacity of the non-metropolitan area is increased, and the limit of voltage stability is found. In addition, by applying the assumed contingencies, the contingency that represents the smallest amount of interface flow limit is found.

However, if an HVDC line is added, it is clearly important from the viewpoint of the overall system because the HVDC lines, due to their nature, are installed at a very important location in the 
system, and the amount of flow in them is much larger than in the conventional AC lines. In addition, because the HVDC lines connect large-scale power generators to metropolitan areas to supply heavy loads, they can satisfy the conditions of the interface lines.

The FV analysis was performed by adding the HVDC line to the interface lines; the resulting change can be observed in Figures 4 and 5, and Table 5. Specifically, the shape of the curve remains unchanged; however, the position of the graph shifts. Although the HVDC lines are included in the interface lines, the fault tolerance that determines the interface flow limits does not change. The interface flow limits differ only in terms of the absolute size and the margin remains unchanged.

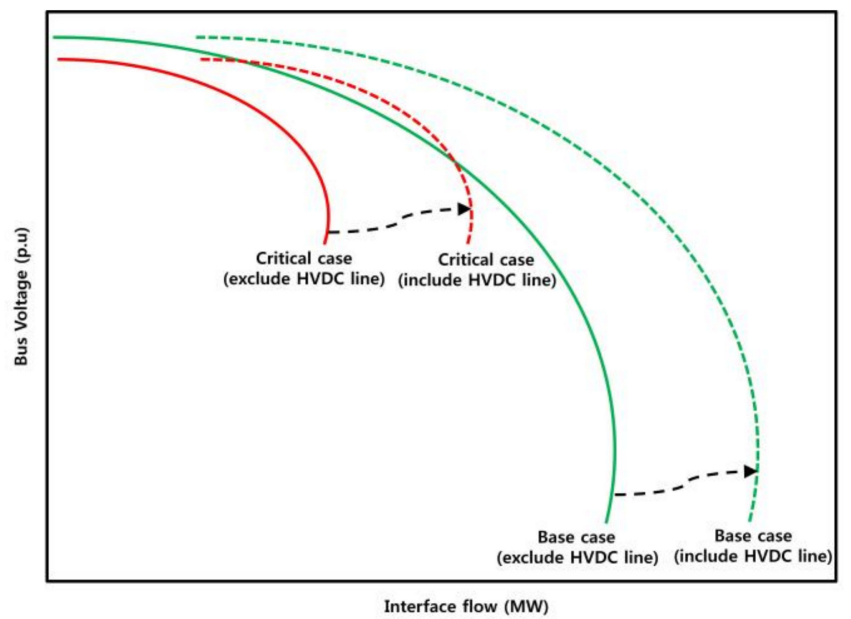

Figure 4. Conceptual FV curve when including the high-voltage direct current (HVDC) line in the interface lines.

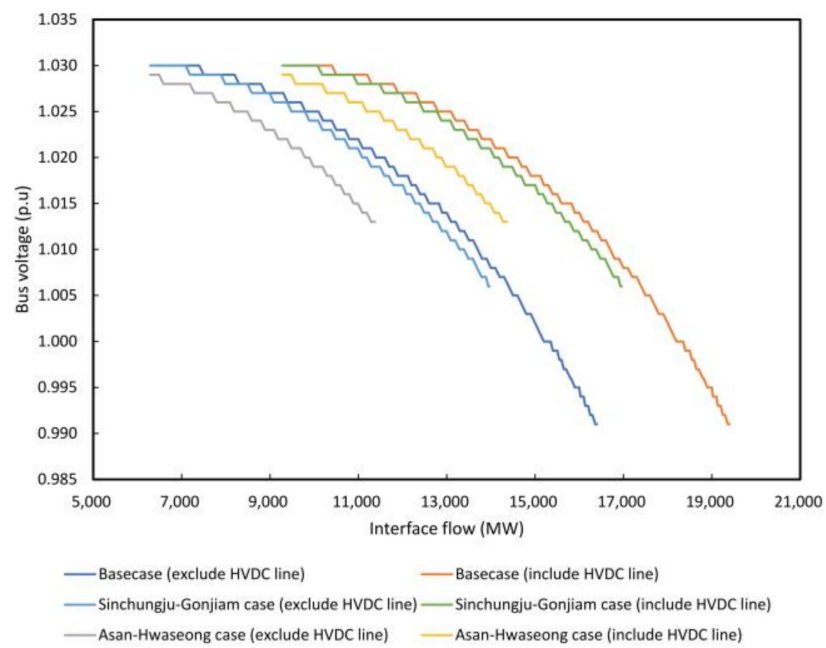

Figure 5. Simulation results of the FV curve when including the HVDC line in the interface lines.

Table 5. Interface power flow margin comparison that includes and excludes the HVDC line

\begin{tabular}{cccc}
\hline \multirow{2}{*}{ No. } & \multirow{2}{*}{ Contingency Case } & \multicolumn{2}{c}{ Interface Flow Margin } \\
\cline { 3 - 4 } & & Exclude HVDC Line & Include HVDC Line \\
\hline 1 & Base Case & $10,000.00$ & $13,000.00$ \\
2 & Sinjoongbu-Sinanseong & 6425.00 & 9425.00 \\
3 & Asan-Hwaseong & 5087.50 & 8087.50 \\
4 & Sinonyang-Seoseoul & 5218.75 & 8218.75 \\
5 & Sinchoongju-Gonjiam & 7681.25 & $10,681.25$ \\
6 & Sinjincheon-Seoanseong & 9412.50 & 9993.75 \\
\hline
\end{tabular}


The above results can be explained easily. In the FV analysis, the flow amount for the interface lines is changed by arbitrarily controlling the power generation, and the flow of the HVDC line is fixed owing to its nature. For example, when the flow amount of the HVDC line is set to $500 \mathrm{MW}$, the flow amount of the HVDC line does not change at $500 \mathrm{MW}$ although the power generation is controlled in the interface flow analysis. Therefore, even if the HVDC lines are included in the interface lines, the flow amount of the interface lines is simply increased to a constant value, but no increase or decrease can be observed.

These results indicate that the HVDC lines do not need to be included in the interface lines when selecting the interface lines in the FV analysis. However, if the HVDC lines are operated by flexibly changing the flow amount in the future, it will be necessary to calculate the interface flow limits more precisely by including the HVDC lines in the interface lines.

\subsection{Simulation Results When Including the HVDC Line Faults in the Contingency List}

The FV analysis was performed by including the HVDC line faults in the contingency list and investigating how the interface flow limits change. Selecting the contingency list is a very important part of the FV analysis because the most likely fault determines the interface flow limits after setting the contingency.

Figures 6 and 7, and Table 6 display the results of the FV analysis that is performed by including the HVDC line faults in the contingency list. These figures confirm that the occurrence of an HVDC line fault is not serious compared to the other existing contingencies. This was an issue in the past, and it was expected that the power system would be affected significantly if the line was disconnected because there was generally a significant amount of flow in the HVDC lines. However, the power system simulation results indicate that the voltage becomes more stable when the HVDC line is disconnected $[6,12]$.

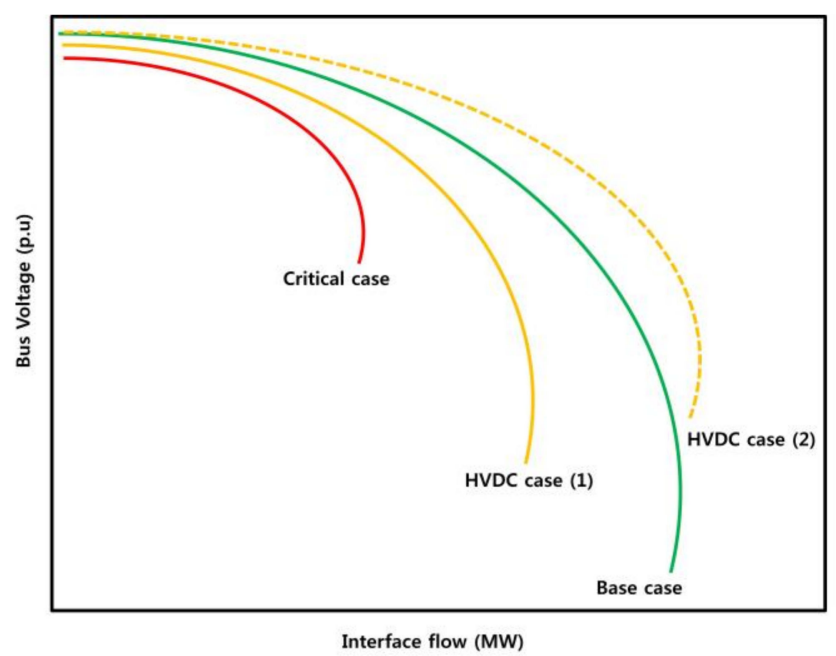

Figure 6. Conceptual FV curve when including the HVDC line fault in the contingency list.

Table 6. Interface power flow margin comparison including the HVDC line fault in the contingency list.

\begin{tabular}{ccc}
\hline No. & Contingency Case & Interface Flow Margin \\
\hline 1 & Base Case & $10,000.00$ \\
2 & Sinjoongbu-Sinanseong & 6425.00 \\
3 & Asan-Hwaseong & 5087.50 \\
4 & Sinonyang-Seoseoul & 5218.75 \\
5 & Sinchoongju-Gonjiam & 7681.25 \\
6 & Sinjincheon-Seoanseong & 9412.50 \\
7 & HVDC 1 & 7714.50 \\
8 & HVDC 2 & $10,000.00$ \\
\hline
\end{tabular}




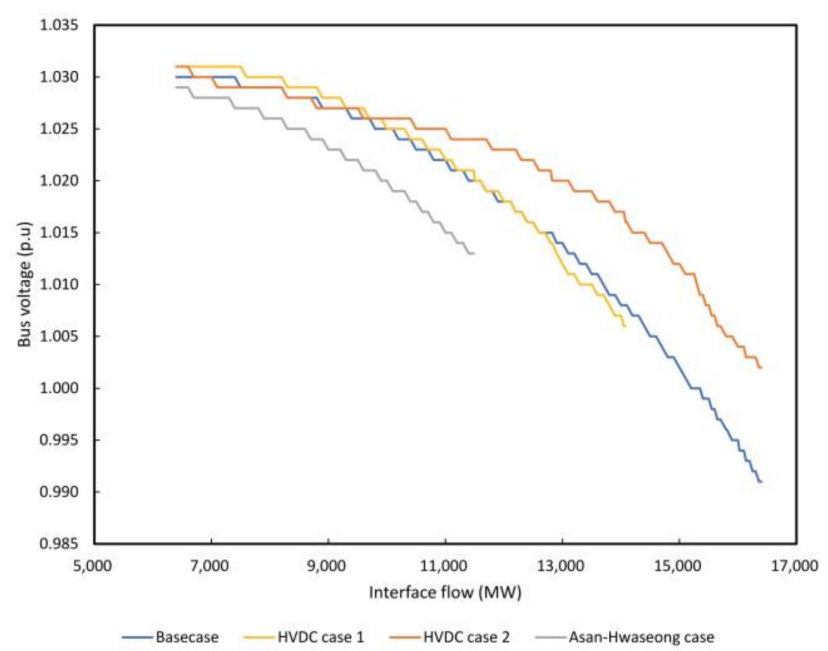

Figure 7. Simulation result of the FV curve when including the HVDC line fault in the contingency list.

This is because a large amount of reactive power is consumed through a filter and a convertor to transmit active power through the HVDC line. Here, if the HVDC line is disconnected and no active power is transmitted, the reactive power consumption stops and a large amount of reactive power remains in the system. This results in improved voltage stability. Figure 5 presents the same result.

However, when the HVDC line is disconnected, the transient stability problem is more likely to occur than the voltage stability problem; therefore, it is necessary to configure the system in advance so the former problem does not occur. However, because KEPCO's system plan has considered this problem in advance, it does not occur in the current system data, even if the HVDC line is disconnected.

In conclusion, it is not important to include the HVDC line faults in the contingency list in the FV analysis. This is because disconnecting the HVDC lines improves the voltage stability and an HVDC line fault is not the most serious fault in the contingency list.

\subsection{Simulation Results of the Interface Flow Margin with and without the DC Tap Control}

Figures 8 and 9, and Table 7 present the simulation results of the interface flow margin with and without the DC Tap control being set up in the FV analysis.

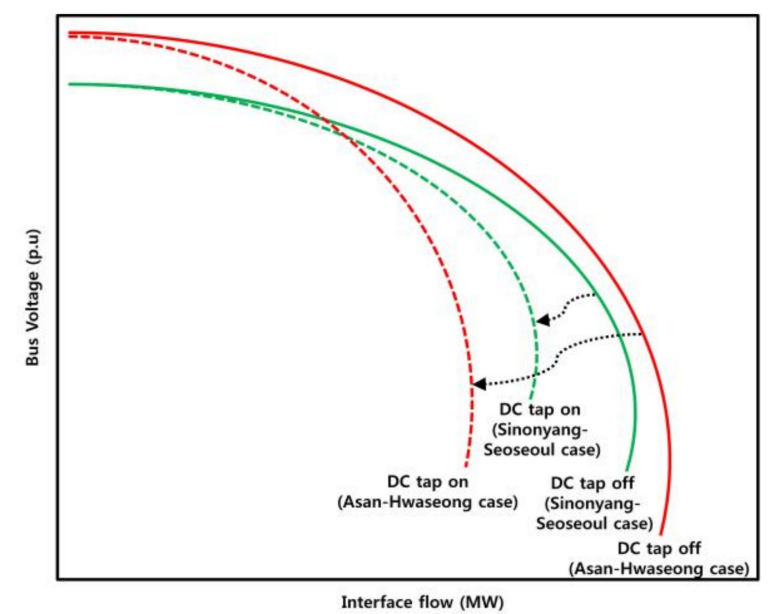

Figure 8. Conceptual FV curve with and without the DC Tap control. 


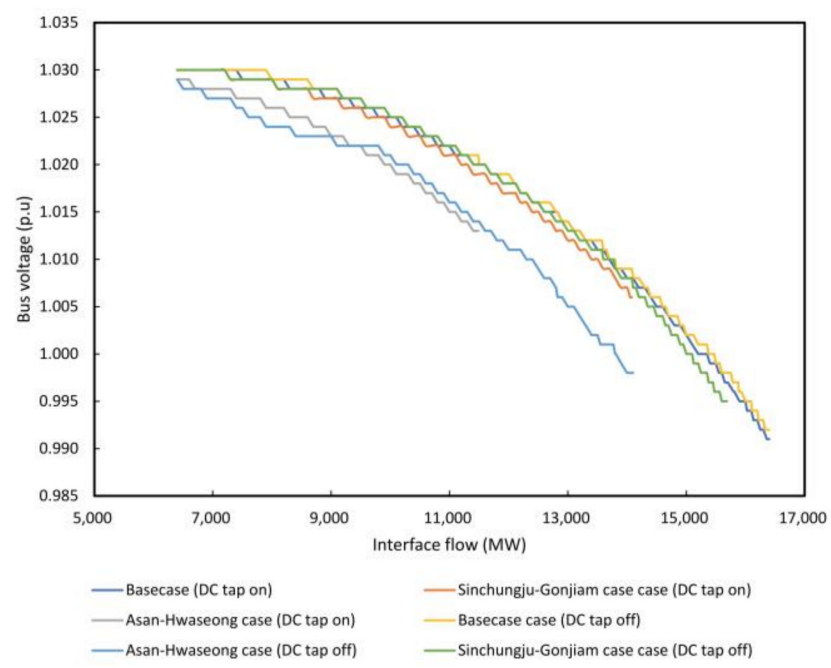

Figure 9. Simulation results of the FV curve with and without the DC Tap control.

Table 7. Interface power flow margin comparison with and without DC Tap.

\begin{tabular}{cccc}
\hline \multirow{2}{*}{ No. } & Contingency Case & \multicolumn{2}{c}{ Interface Flow Margin } \\
\cline { 3 - 4 } & & DC Tap On & DC Tap Off \\
\hline 1 & Base Case & $10,000.00$ & $10,000.00$ \\
2 & Sinjoongbu-Sinanseong & 6425.00 & 9531.25 \\
3 & Asan-Hwaseong & 5087.50 & 7700.00 \\
4 & Sinonyang-Seoseoul & 5218.75 & 7412.50 \\
5 & Sinchoongju-Gonjiam & 7681.25 & 9287.50 \\
6 & Sinjincheon-Seoanseong & 9412.50 & 9993.75 \\
\hline
\end{tabular}

Figure 9 confirms that the interface flow margin is higher when the DC Tap is not controlled. This is because each system bus voltage decreases when a two-line fault occurs in the interface lines; therefore, DC Tap switching is performed in an HVDC converter station to match the rated voltage for the HVDC transmission. In this situation, the additional reactive power is consumed to raise the voltage of the relevant bus. Therefore, if the DC Tap is controlled, the reactive power margin is reduced in comparison to the DC Tap when it is not controlled. In addition, the interface flow limits are considered to be reduced. If the DC Tap is not controlled, there is no need to further add reactive power because the HVDC transmission continues regardless of the voltage drop of the power system. As a result, the interface flow limits are considered to be higher than those when the DC Tap is controlled.

The worst-case scenarios always determine the interface flow limits in the FV analysis because they are specified in the power system reliability notice. As a result, the power system is managed in a stable manner in any situation. The interface flow limits are generally smaller when the DC Tap is controlled. Therefore, it is necessary to perform the FV analysis since the DC Tap must be controlled in the future FV analysis. This can be used to prepare for the worst-case scenarios of the power system operation and manage the interface flow limits.

Whether the DC Tap is controlled strongly influences the calculation of the interface flow limits. Therefore, it is necessary to perform the FV analysis by closely reflecting the effect of the DC Tap to obtain the accurate interface flow limits. Furthermore, the DC Tap parameters should be accurately modeled and set based on the HVDC operating conditions.

\section{Conclusions}

This study investigates three issues in performing the FV analysis to accurately calculate the interface flow limits while considering the increasingly extensive installation of the HVDC facilities in the land power systems. The results indicate that the HVDC lines do not need to be included 
in the interface lines because doing so does not change the interface flow limits. Furthermore, the HVDC line faults do not need to be included in the contingency list because they are not the most serious contingency. Finally, the interface flow limits are relatively low when the DC Tap is controlled. When operating the system, the worst-case scenarios must be considered. Therefore, the interface flow limits should be calculated by controlling the DC Tap in the future.

The results of this study should be considered when establishing a transmission substation operation plan and a transmission facility construction plan. Furthermore, the interface flow limits should be calculated by thoroughly analyzing the effects of the DC Tap, clearly defining them, and applying the correct parameters. In addition, related studies should be conducted to accurately analyze the interface flow limits for the future KEPCO systems that include multiple technologies such as a thyristor-controlled series capacitor, a back-to-back HVDC, and HVDC.

Funding: This work was supported by the National Research Foundation of Korea [2017R1D1A1B03034460] and Korea Electric Power Corporation [Grant number: R18XA06-65].

Conflicts of Interest: The authors declare no conflict of interest.

\section{References}

1. Lee, B.; Song, H.; Kwon, S.-H.; Jang, G.; Kim, J.-H.; Ajjarapu, V. A study on determination of interface flow limits in the KEPCO system using modified continuation power flow (MCPF). IEEE Trans. Power Sys. 2002, 17, 557-564.

2. Han, S. A study on calculation of interface power flow margin by HVDC expansions in mainland and DC tap setting. Trans. Korean Inst. Electr. Eng. 2019, 68, 212-217. [CrossRef]

3. Kim, T.-G.; Lee, B.-J.; Song, H.-C.; Kang, B.-I.; Jo, J.-M. Calculation of the optimal load shedding amount and location considering interface flow limit. In Proceedings of the Korean Institute of Electrical Engineers Conference, Muju, Korea, 14-17 July 2009.

4. Lee, Y.; Han, S. A study on the tripping scheme of generator based on transient stability analysis. Trans. Korean Inst. Electr. Eng. 2019, 68, 89-94. [CrossRef]

5. Ministry of Trade, Industry and Energy. The 8th Basic Plan for Power Supply. Available online: https://www. motie.go.kr/common/download.do?fid=bbs\&bbs_cd_n=81\&bbs_seq_n=159970\&file_seq_n=3 (accessed on 14 December 2017).

6. Han, S.-Y.; Gwon, D.-H.; Chung, I.-Y.; Lim, J.-B. A study on the impact of HVDC transmission system to interconnect large-scale power generation plants to power grid in Korea. Trans. Korean Inst. Electr. Eng. 2013, 62, 1647-1656. [CrossRef]

7. Lefebvre, D.; Moors, C.; Van Cutsem, T. Design of an undervoltage load shedding scheme for the Hydro-Quebec system. In Proceedings of the 2003 IEEE Power Engineering Society General Meeting (IEEE Cat. No.03CH37491), Toronto, ON, Canada, 13-17 July 2003; Volume 4, pp. 2030-2036.

8. Lefebvre, D.; Bernard, S.; Van Cutsem, T. Undervoltage load shedding scheme for the Hydro-Quebec system. In Proceedings of the IEEE Power Engineering Society General Meeting, Denver, CO, USA, 6-10 June 2004; Volume 2, pp. 1619-1624.

9. Moors, C.; Lefebvre, D.; Van Cutsem, T. Design of load shedding schemes against voltage instability. In Proceedings of the 2000 IEEE Power Engineering Society Winter Meeting, Conference Proceedings (Cat. No.00CH37077), Singapore, 23-27 January 2000; Volume 2, pp. 1495-1500.

10. Moors, C.; Lefebvre, D.; Van Cutsem, T. Load shedding controllers against voltage instability: A comparison of designs. In Proceedings of the 2001 IEEE Porto Power Tech. Proceedings (Cat. No.01EX502), Porto, Portugal, 10-13 September 2001; Volume 2, p. 6.

11. Yoo, J.-H.; Hur, J.; Cha, J.-M.; Kim, T.-G.; Kang, B.-I.; Cho, S.-H. Determination of reasonable amounts of under-voltage load shedding for $765 \mathrm{kV}$ T/L according to the power system reliability standards. Trans. Korean Inst. Electr. Eng. 2015, 64, 845-851. [CrossRef]

12. Hwang, S.; Lee, J.; Hwang, P.; Yoon, M.; Jang, G. Analysis of system power flow margin on replacement of transmission line to DC line. In Proceedings of the Korean Institute of Electrical Engineers Conference, Muju, Korea, 15-17 July 2015. 
13. Hwang, S.-W.; Kim, J.-H.; Lee, B.-H.; Kim, Y.-H.; Kwak, N.-H. A study on the development of a determining process to enhance inter-area TTC. In Proceedings of the Korean Institute of Electrical Engineers Conference, Seoul, Korea, 17-20 November 2002.

14. Kim, B.-H.; Jeong, H.; Chang, D.-H.; Eom, T.-S.; Kim, H. Evaluation of impacts on the voltage and tie-line flow changes in the metropolitan area caused by new HVDC lines. In Proceedings of the Korean Institute of Electrical Engineers Conference, Yongpyeong, Korea, 11-13 July 2018.

15. Song, H.; Kim, S.; Lee, B.; Kwon, S.; Ajjarapu, V. Determination of interface flow margin using the modified continuation power flow in voltage stability analysis. IEE Proc. Gener. Transm. Distrib. 2001, 148, 128-132. [CrossRef]

16. Hou, G.; Vittal, V. Determination of Transient Stability Constrained Interface Real Power Flow Limit Using Trajectory Sensitivity Approach. IEEE Trans. Power Syst. 2013, 28, 2156-2163. [CrossRef]

17. Kamh, M.Z.; Iravani, R. Steady-State Model and Power-Flow Analysis of Single-Phase Electronically Coupled Distributed Energy Resources. IEEE Trans. Power Deliv. 2012, 27, 131-139. [CrossRef]

18. Tong, J. Real time transfer limit calculations. In Proceedings of the 2000 Power Engineering Society Summer Meeting (Cat. No.00CH37134), Seattle, WA, USA, 16-20 July 2000; Volume 2, pp. 1297-1302.

19. Li, Y. Power Compensation Control for Interconnection of Weak Power Systems by VSC-HVDC. IEEE Trans. Power Deliv. 2017, 32, 1964-1974. [CrossRef]

20. Mehrasa, M.; Pouresmaeil, E.; Zabihi, S.; Catalão, J.P.S. Dynamic Model, Control and Stability Analysis of MMC in HVDC Transmission Systems. IEEE Trans. Power Deliv. 2017, 32, 1471-1482. [CrossRef]

21. Zhao, W.; Guo, Q.; Sun, H.; Ge, H.; Li, H. Practical short-term voltage stability index based on voltage curves: Definition, verification and case studies. IET Gener. Transm. Distrib. 2018, 12, 4292-4300. [CrossRef]

22. Xu, Z.; Xu, Z.; Xiao, L. Analysis and assessment standards of power stability of multi-send HVDC systems. J. Eng. 2019, 2019, 748-753. [CrossRef]

23. Lee, B.; Kang, S.; Seo, S.; Ajjarapu, V.; Song, H. Generation re-dispatch algorithm against voltage collapse in Jeju island system with a frequency control by high-voltage direct current. IET Gener. Transm. Distrib. 2010, 4, 609-619. [CrossRef]

24. Study on Improvement of Power System Voltage Control and Operation Method to Maintain Voltage Stability, Final Report; KPX: Seoul, Korea, 7 August 2017.

25. Rahman, H.; Khan, B.H. Power Upgrading of Transmission Line by Combining AC-DC Transmission. IEEE Trans. Power Syst. 2007, 22, 459-466. [CrossRef]

26. Imdadullah; Amrr, S.M.; Jamil Asghar, M.S.; Ashraf, I.; Meraj, M. A Comprehensive Review of Power Flow Controllers in Interconnected Power System Networks. IEEE Access 2020, 8, 18036-18063. [CrossRef]

27. Li, B.; Liang, Y.; Wang, G.; Li, H.; Chen, X. A Control Parameter Design Method for Hybrid Multi-Terminal HVDC System. IEEE Access 2020, 8, 18669-18680. [CrossRef]

28. Xia, C.; Li, X.; Li, S.; Zhou, B. Definition and Analysis of Receiving System Voltage Support Strength Factor. IEEE Access 2019, 7, 134206-134214. [CrossRef]

29. Rouzbehi, K.; Heidary Yazdi, S.S.; Shariati Moghadam, N. Power Flow Control in Multi-Terminal HVDC Grids Using a Serial-Parallel DC Power Flow Controller. IEEE Access 2018, 6, 56934-56944. [CrossRef]

30. Study on Seoul Metropolitan Area Power Grid Optimal Configuration Plan, Final Report; KPX: Seoul, Korea, 12 February 2015.

31. Kang, S.; Seo, S.; Lee, B.; Chang, B.; Myung, R. Centralized Control Algorithm for Power System Performance using FACTS Devices in the Korean Power System. J. Elect. Eng. Technol. 2010, 5, 353-362. [CrossRef]

32. Siemens PTI. PSS/E 33 Operation Manual. Available online: https://pss-store.siemens.com/: (accessed on 4 May 2020).

(C) 2020 by the author. Licensee MDPI, Basel, Switzerland. This article is an open access article distributed under the terms and conditions of the Creative Commons Attribution (CC BY) license (http://creativecommons.org/licenses/by/4.0/). 